\title{
Hipertansif Hastalarda Kalp Hızı Değişkenliği ile Kardiyovasküler Risk Faktörlerinin ilişkisi
}

\section{The Relationship Between Heart Rate Variability and Cardiovascular}

\author{
Risk Factors in Hypertensive Patients
}

\author{
Alper Çil', Efe Edem², Özhan Göldeli² \\ ' Uşak Eğitim ve Araştırma Hastanesi, Kardiyoloji \\ ${ }^{2}$ Izmir Tınaztepe Hastanesi, Kardiyoloji \\ ${ }^{3}$ İzmir Dokuz Eylül Üniversitesi Tıp Fakültesi Hastanesi, Kardiyoloji
}

Yazışma Adresi / Correspondence:

Efe Edem

Ahmet Piriştina Blv. No:51 Tınaztepe, Buca, İzmir | Türkiye

$\mathrm{T}:$ +90 $5335906187 \quad$ E-mail: edemefe@gmail.com

Geliş Tarihi / Received : 04.01.2018 Kabul Tarihi / Accepted : 10.04.2018




Sakarya TIp Dergisi 2018;8(2):303-310

\section{Giriş}

Kalp hızı, kardiyovasküler risk öngörmede yeni geliştirilmiş bir risk faktörüdür. SHIFT çalışmasından elde edilen veriler sonrası kalp hızı önemli hale gelmiştir. ${ }^{1}$ Büyük çalışmalardan elde edilen veriler kalp hızının sadece bir risk belirteci olmasından ziyade artık önemli bir risk faktörü olduğunu göstermektedir. Birçok çalışmadan elde edilen veriler kalp hızının kardiyovasküler ölümler, tüm nedenlere bağı ölümler ve major kardiyak olaylarda artış için önemli bir risk faktörü olduğunu göstermektedir. TNT çalışmasından gelen geriye doğru gerçekleştirilen analiz verileri, kalp hızının 70 vuru/dk'nın üzerinde olmasının kardiyovasküler prognoz açısından olumsuz etkilere neden olduğunu göstermektedir. ${ }^{2}$ BEAUTIFUL çalışmasının sonuçlarında da görüldüğü gibi 70 vuru/dk ve üzeri kalp hızı, bilinen kararlı koroner arter hastalarında kardiyovasküler ölümler için önemli risk artışına yol açmaktadır. ${ }^{3}$ Kalp hızı ve kalp hızı değişikliği ile kardiyovasküler yanıtı inceleyen az sayıda çalışma mevcuttur. Otonom sinir sistemi, esansiyel arteryel hipertansiyonun patogenezinde önemli bir rol oynamaktadır. Yapılan çalışmalarda hipertansif hastalarda kardiyak otonom disfonksiyonun rol oynadığı gösterilmiştir. Otonom sinir sisteminin süregelen dengesizliği advers kardiyak olaylar için önemli bir risk faktörüdür. Bir dizi anlık kalp hızından, özellikle de siklik intervallerin 24 saat gibi uzun dönemli kayıtlarından birden fazla istatistiksel zaman bağımlı kalp hızı değişkenlik ölçümü yapılabilir. Bunların arasında standard deviations for all R-R intervals (SDNN) en sık kullanılan zaman bağımlı kalp hızı değişkenliği metodudur. SDNN'nin major komponentini gece ve gündüz arasındaki NN intervallerindeki farklılık meydana getirmektedir. Standard deviation of all R-R intervals in successive five-minute epochs (SDANN); 5 dakikalık NN interval ortalamalarının standart deviasyonudur ve uzun dönem kalp hızı dalgalanmaları konusunda daha iyi bilgi vermektedir. SDANN, anormal ritmlerden daha az etkilenmektedir ve atrial fibrilasyonda risk stratifikasyonu yapılmasına olanak sağlamaktadır. ${ }^{4,5}$ Heart Rate Variability (HRV) triangular indeks; tüm NN interval sayısının, geometrik yapıdaki en yüksek dansiteyi oluşturan NN interval miktarına bölümüdür. HRV'nin kısa dönem komponentleri ise root-mean square differences of successive R-R intervals (RMSSD) ile değerlendirilir. Kardiyovasküler hastalığın etiyolojisini ortaya koymada, klasik major risk faktörleri bazı hastalarda yeterli olmamaktadır. Bu nedenle yeni risk belirteçlerinin saptanmasına, yeni önleyici ve terapötik yaklaşımlara gerek duyulmaktadır. Arteryel elastisite; sabit bir damar uzunluğunda belirli bir basınç için mutlak çap (ya da alan) değişikliği yani arteryel duvarların genişleyebilirliğidir. Stiffness (sertlik) ise; damar duvarında elastik doku kaybından kaynaklanan damar katılaşması ve bunun sonucunda da arteryel elastisitenin azalmasıdır. Arteryel stiffness; sigara, hiperkolesterolemi, hipertansiyon, diabetes mellitus (DM), gibi bilinen aterosklerotik risk faktorlerinin artışı ve yaşlanmanın sonucu olarak meydana gelmektedir. ${ }^{6,7}$ Artmış aortik stiffness veya azalmış kompliyans; damar sisteminin yaygın aterosklerotik tutulumunun göstergesidir. ${ }^{8,9} \mathrm{Ar}$ teryel stiffnessın değerlendirilmesinde çeşitli parametreler tanımlanmıştır. Kateter bazlı girişimsel ölçümlerin pratik olmaması nedeni ile girişimsel olmayan yöntemler geliştirilmiştir. Transtorasik ekokardiyografideki (TTE) aort çapı, sfigmomanometrik kan basıncı ölçümü ile aortik strain ve aortik distensibilite hesaplanabilir. Aynı zamanda arteryel tonometri cihazı vasıtasıyla ölçülen nabız dalga hızı ve augmentasyon indeksi, arteryel stiffness tayininde en sık kullanılan girişimsel olmayan yöntemlerdir. Arteryel kompliyansı ve stiffnessi indirekt olarak ölçmede en sık nabız dalga hızı (NDH) kullanılmaktadı ${ }^{10,11}$. Girişimsel olmayan şekilde elde edilen bu parametrelerle girişimsel olarak elde edilenlerin benzer olduğu gösterilmiştir ${ }^{12}$. Bir çok çalışmada karotis intima-media kalınlığı (KIMK) ile koroner arter hastalığı (KAH) sıklığı arasındaki ilişki tespit edilmiştir. Benzer şekilde KiMK yaygınlığı ve derecesi, kardiyovasküler risk faktörleri ve semptomatik KAH'nın yaygınlığı ile ilişkili bulunmuştur. Çalışmamızın amacı kalp hızı, kalp hızı değişkenliği ile yeni geliştirilmiş olan kar- 
diyovasküler risk faktörleri arasındaki ilişkiyi değerlendirmek, kalp hızı ve kalp hızı değişiminin risk faktörü olarak kullanılabilirliğini öngörmeye çalışmaktır.

\section{Gereç ve Yöntem}

\section{Hasta Seçimi}

Araştırma protokolü için hastanemizin girişimsel olmayan klinik araştırmalar etik kurulundan izin alındı. Araştırmaya dahil edilmek üzere Eylül 2017 tarihinde kardiyoloji kliniğine tansiyon yüksekliği ile başvuran ve/veya takipte olan hastalar, dahil edilme - hariç edilme kriterlerine uygun olarak çalışmaya dahil edildi. Tanımlayıcı tipte olan bu çalışma için uygun kriterleri taşıyan hastaların, poliklinikten alınan anamnezleri, rutin biyokimyasal test sonuçları, daha önce yapılmış olan TTE ve Holter elektrokardiyografi (EKG) raporları incelendi. Holter EKG si olmayan hastalardan 24 saatlik holter EKG kaydı alındı. Tonometri cihazı ile nabız dalga hızları belirlendi. Tarafımızca PHILIPS (Amsterdam, Hollanda) marka ekokardiyografi cihazının doku probu ile KiMK ölçüldü.

\section{Dahil edilme kriterleri}

Kardiyoloji polikliniğine tansiyon yüksekliği ile başvuran ve/veya kontrole gelen 18-80 yaş arası bilinen KAH olmayan hastalar dahil edildi.

\section{Dışlama kriterleri}

1. Aort anevrizması olan hastalar

2. Daha önceden bilinen koroner arter hastalığı olanlar

3. Atriyal fibrilasyon, atriyal flutter, diğer taşiaritmi ve bradiaritmileri mevcut hastalar

4. DM tanisı olanlar

5. Beta blokör ve/veya kalsiyum kanal blokörü kullananlar

6. Ciddi sol ventrikül sistolik fonksiyon bozukluğu $(E F<\% 40)$ olanlar.

7. Bilinen periferik damar hastalı̆ı olanlar

8. Kronik karaciğer ve böbrek yetmezliği olanlar

9. Konjenital kalp hastalığı olanlar

10. Aortu tutan sistemik hastalkkğı (Marfan, Ehler-Danlos gibi) olanlar

11. Kronik obstrüktif akciğer hastalığı gibi solunum sistemi rahatsızlıkları bulunanlar

\section{Nabız Dalga Hızı (NDH) Ölçümü}

Nabız dalga hızı, SphygmoCor (AtCor Medical Instruments) markalı tonometri cihazı kullanılarak hesaplandı. Ventriküler kontraksiyon tarafından oluşturulan basınç nabzı, aort boyunca bir dalga olarak seyreder. Nabız dalga hızını, arteryal sistemin farkı iki noktasında bulunan kan basıncı eğrileri arasındaki gecikmeden hesaplamak mümkündür. Hastaların karotis ve radial arter basınç dalga formları, basınca duyarlı transduser yardımı ile boyun ve sağ ön kolda ilgili yerlere konularak noninvaziv olarak ölçüldü. Bu iki basınç dalga eğrisi arasındaki gecikme ile karotis-radial arter arasındaki yüzeyel mesafe kullanılarak NDH hesaplandı.

\section{Holter EKG}

Araştırmaya alınan hastaların Delmar Reynolds (Hertford, UK) marka ritmholter cihazları ile holter EKG kayıtları yapıldı. Alınan 24 saatlik EKG kayıtlarından yapılan zaman bağımlı kalp hızı analizlerinde ortalama RR süresi, 24 saat triangle indeks, SDNN, SDNNi, SDANN, RMSSD değerleri elde edildi. Hastaların maksimal kalp hızı, minimal kalp hızı, 24 saatlik ortalama kalp hızı, ortalama
Sakarya Tıp Dergisi

2018;8(2):303-310

Çil ve Ark.

Hipertansif Hastalarda Kalp Hızı Değişkenliği ile

Kardiyovasküler Risk Faktörlerinin ilişkisi 
Sakarya TIp Dergisi 2018;8(2):303-310 gecelik kalp hızları alındı.

\section{İstatistiksel Yöntemler}

ìstatistiksel analizler SPSS 11.0 (New York, USA) programıyla yapıldı. Sürekli değişkenler ortalama \pm standart sapma, kategorik değişkenler ise frekans ve yüzde ile ifade edildi. Kategorik değişkenler için Chi-Square Testi yapıldı. Dağılım örneğine uygun olacak şekilde sürekli değişkenlerin analizi için Mann-Whitney U testi uygulandı. Sürekli değişkenler arası ilişki Spearman Korelasyon analizi ile incelendi. Korelasyon saptanan parametreler için lineer regresyon analizi ile model oluşturuldu. İstatistiksel analizler yapılırken $p<0.05$ değeri istatistiksel olarak anlamlı kabul edildi.

\section{Bulgular}

Çalışmaya 18'i kadın (\%28.5) , 45’i erkek (\%71.5) olmak üzere toplam 63 ardışık hasta dahil edildi. Çalışma hastalarının yaş ortalaması $51.6 \pm 10$ (37 ile 72 yaş arası) idi. Ortalama sistolik kan basınçları $141.7 \pm 13.5 \mathrm{mmHg}$, diyastolik kan basınçları $75.3 \pm 6.9 \mathrm{mmHg}$, ortalama istirahat

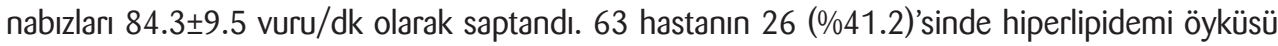
mevcuttu. 29 (\%46)'u sigara kullanmakta ve 32 (\%50.7)'sinin birinci derece akrabalarından en az birinde kardiyovasküler hastalık öyküsü yer almaktaydı. Tüm hastaların demografik özellikleri Tablo 1 'de özetlenmiştir.

\begin{tabular}{|c|c|}
\hline Yaş (ortalama \pm SD*) & $51.6 \pm 10$ \\
\hline Cinsiyet (Kadın/Erkek) & $18 / 45$ \\
\hline Boy (ortalama \pm SD*) & $173.6 \pm 9.9$ \\
\hline Kilo (ortalama \pm SD*) & $85.2 \pm 10$ \\
\hline Vücut Kitle İndeksi (ortalama \pm SD*) & $27.4 \pm 3.7$ \\
\hline Nabız (ortalama \pm SD*) & $84.3 \pm 9.5$ \\
\hline Sistolik Kan Basıncı (mmHg) (ortalama \pm SD*) & $141.7 \pm 13.5$ \\
\hline Diastolik Kan Basıncı (mmHg) (ortalama \pm SD*) & $75.3 \pm 6.9$ \\
\hline Hiperlipidemi $\left(\mathrm{n}^{* *}, \%\right)$ & $26(41.2)$ \\
\hline Sigara Kullanımı $\left(\mathrm{n}^{* *}, \%\right)$ & $29(46)$ \\
\hline Aile Öyküsü $\left(n^{* *}, \%\right)$ & $32(50.7)$ \\
\hline Açlık Kan Şekeri (ortalama \pm SD*) & $98.8 \pm 10.2$ \\
\hline Total Kolesterol (ortalama \pm SD*) & $206.3 \pm 19.5$ \\
\hline LDL (mg/dl) (ortalama \pm SD*) & $134.8 \pm 17.8$ \\
\hline HDL (mg/dl) (ortalama \pm SD*) & $36.9 \pm 7.8$ \\
\hline Trigliserid (mg/dl) (ortalama \pm SD*) & $167 \pm 26.6$ \\
\hline
\end{tabular}

Tablo 2'de görülebileceği gibi çalışmaya dahil edilen hastaların 24 saatlik holter EKG kayıtlarından maksimum kalp hızı (121.7 \pm 7.1 vuru/dk), minimum kalp hızı (57.6 \pm 7.8 vuru/dk), 24 saatlik ortalama kalp hızı ( $75 \pm 7.1 \mathrm{vuru} / \mathrm{dk})$, gecelik ortalama kalp hızı (65.6 \pm 8.7 vuru/dk) ve kalp hızı değişkenliği parametreleri elde edildi. NDH değerleri $5.7 \pm 0.4$, augmentasyon indeksi $\% 20.5 \pm 2.8$ ve KiMK ortalama $0.87 \pm 0.09 \mathrm{~mm}$ olarak bulundu.

Tablo 3 ve 4'de görüldüğü üzere hastalar gecelik kalp hızı median (65 vuru/dk) değerine göre 2 gruba ayrıldığında hastaların demografik özellikleri ve NDH değerleri arasında anlamlı farklılık sap- 
tanmamakla birlikte, KiMK değerlerinde anlamlı fark saptandı (p:0.04).

\begin{tabular}{|l|l|}
\hline \multicolumn{2}{|l|}{ Tablo 2: Tüm hastaların klinik verileri } \\
\hline Maksimum Kalp Hızı (vuru/dk) & $121.7 \pm 7.1$ \\
\hline Minimum Kalp Hızı(vuru/dk) & $57.6 \pm 7.8$ \\
\hline 24 Saatlik Kalp Hızı (vuru/dk) & $75 \pm 7.1$ \\
\hline Ortalama Kalp Hızı Gece (vuru/dk) & $65.6 \pm 8.7$ \\
\hline SDNN & $141 \pm 13.7$ \\
\hline SDANN & $127 \pm 13.5$ \\
\hline RMSSD & $31.7 \pm 8.1$ \\
\hline Triangle indeks & $33.2 \pm 7.9$ \\
\hline Pulse Wave Velosite (m/s) & $5.7 \pm 0.45$ \\
\hline Augmentasyon indeksi & $\% 20.5 \pm 2.8$ \\
\hline Karotis İntima-Media Kalınlığı (mm) & $0.87 \pm 0.09$ \\
\hline $\begin{array}{l}\text { SDNN: standard deviations for all R-R intervals, SDANN: standard deviation of all R-R intervals in successive } \\
\text { five-minute epochs, RMSDD: root-mean square differences of successive R-R intervals }\end{array}$ \\
\hline
\end{tabular}

Tablo 3: Gecelik kalp hızına göre ayrılan grupların demografik özellikleri

\begin{tabular}{|l|c|c|c|}
\hline & $\begin{array}{c}\text { Kalp Hızı Gece } \\
\leq 65 \text { vuru/dk }\end{array}$ & $\begin{array}{c}\text { Kalp Hızı Gece } \\
\geq 66 \text { vuru/dk }\end{array}$ & $P$ \\
\hline Yaş (ortalama $\pm \mathrm{SD}^{*}$ ) & $49.5 \pm 10.7$ & $52.3 \pm 9.4$ & 0.513 \\
\hline Boy (ortalama $\pm \mathrm{SD}^{*}$ ) cm & $176 \pm 9.5$ & $171.2 \pm 9.9$ & 0.066 \\
\hline Kilo (ortalama $\left.\pm \mathrm{SD}^{*}\right) \mathrm{kg}$ & $87.1 \pm 9.3$ & $83.3 \pm 10.5$ & 0.189 \\
\hline Vücut Kitle İndeksi (ortalama $\left.\pm \mathrm{SD}^{*}\right)$ & $26.9 \pm 2.7$ & $27.3 \pm 3.6$ & 0.211 \\
\hline Nabız (ortalama $\left.\pm \mathrm{SD}^{*}\right)$ vuru/dk & $80.3 \pm 10.4$ & $88.3 \pm 6.4$ & 0.069 \\
\hline Sistolik Kan Basıncı (mmHg) (ortalama $\pm \mathrm{SD}^{*}$ ) & $143.5 \pm 14.2$ & $138.9 \pm 12.6$ & 0.239 \\
\hline Diastolik Kan Basıncı (mmHg) (ortalama $\left.\pm \mathrm{SD}^{*}\right)$ & $74.7 \pm 5.4$ & $76.8 \pm 6.1$ & 0.453 \\
\hline * SD: Standart Deviasyon & & \\
\hline
\end{tabular}

Tablo 4: Gecelik kalp hızlarına göre ayrılan grupların verileri

\begin{tabular}{|l|c|c|c|}
\hline & $\begin{array}{c}\text { Kalp Hızı Gece } \\
\leq 65 \text { vuru/dk }\end{array}$ & $\begin{array}{c}\text { Kalp Hızı Gece } \\
\geq 66 \text { vuru/dk }\end{array}$ & $P$ \\
\hline SDNN & $137.3 \pm 12$ & $142.6 \pm 1$ & 0.059 \\
\hline SDANN & $126 \pm 12.1$ & $128 \pm 14.9$ & 0.244 \\
\hline Triangleindeks & $29.8 \pm 5.7$ & $30.5 \pm 4.7$ & 0.342 \\
\hline Pulse Wave Velosite (m/s) & $31.6 \pm 7.8$ & $34.8 \pm 7.8$ & 0.104 \\
\hline Augmentasyon indeksi & $5.6 \pm 0.3$ & $5.8 \pm 0.51$ & 0.182 \\
\hline Karotis İntima-Media Kalınlığı(mm) & $20 \pm 2.2$ & $21 \pm 3.2$ & 0.146 \\
\hline
\end{tabular}

SDNN: standard deviations for all R-R intervals, SDANN: standard deviation of all R-R intervals in successive five-minute epochs, RMSDD: root-mean square differences of successive R-R intervals

Klasik risk faktörleri açısından (cinsiyet, hipertansiyon, sigara, aile öyküsü) hastalar incelendiğinde; kadın cinsiyette HDL düzeyi ( $\rho: 0.015)$, maksimum kalp hızı ( $p: 0.005)$, minimum kalp hızı ( $p: 0.011)$, ortalama kalp hizı gece ( $p: 0.019)$, puls wave velosite (PWV) ( $p: 0.002)$ ve augmentasyon indeksi (p:0.008) anlamlı oranda daha yüksek bulunmuştur.

Hastalar hipertansiyon sürelerine göre 4 gruba ayrıldıklarında (yeni tanı, 0-5 yıl, 5-10 yıl, 10 ve
Sakarya Tıp Dergisi

2018;8(2):303-310

Çil ve Ark.
Hipertansif Hastalarda Kalp Hız Değiskenliği ile

Kardiyovaskúler Risk Faktörlerinin ilişkisi 
Sakarya TIp Dergisi 2018;8(2):303-310 üzeri) PWV (p:0.996), augmentasyon indeksi (p:0.597) ve KiMK (p:0.515) açısından anlamlı fark saptanmadı. Daha önce yapılmış çalışmalara bakıldığında hipertansiyon tanı süresi ile PWV, AUG indeksi ve KiMK arasında anlamlı korelasyon mevcuttur.

Sigara kullanan ve kullanmayan hastaları karşılaştırdığımızda ise boy ile sigara kullananlar arasında anlamlılık saptanmıştır ( $p: 0.03$ ). Bu durum erkek hastalarda sigara içiminin daha fazla olması ile açıklanabilir. Sigara içen hastaların bazal kalp hızı, SDANN ( $p: 0.012)$, triangle indeks ( $p: 0.044)$ ve gece/gün kalp hızı oranı ( $p: 0.019$ ) anlamlı olarak daha yüksek bulunmuştur. Daha önceki yayınlara benzer olarak sigaranın kalp hızını artırıcı etkisi saptanmıştır.

\section{Tartışma}

20. yüzylın başlarında kardiyovasküler hastalıklar (KVH), tüm dünyadaki ölüm nedenlerinin \%10'undan azını oluşturmaktayken bu oran zaman içinde giderek artmış ve 21. yüzyılın başından itibaren KVH gelişmiş ülkelerdeki ölüm sebeplerinin \%50'sinden, gelişmekte olan ülkelerdeki ölüm sebeplerinin $\% 25$ 'inden sorumlu hale gelmiştir. ${ }^{13}$ Geleneksel kardiyovasküler risk faktörleri ile kardiyovasküler olaylar arasındaki ilişki net olarak ortaya konmuş olmasına rağmen, miyokard infarktüsü geçiren hastaların yaklaşık olarak yarısında lipid seviyelerinin normal saptanmış ${ }^{14}$ ve prematür koroner arter hastalığı saptanan hastaların çoğunda herhangi bir risk faktörü saptanamamıştır. Yapılan yeni çalışmalarla birlikte inflamasyonun, koroner kalp hastalığının patofizyolojisinde önemli bir rolü olduğu anlaşılmıştır. İnterlökin 6, CRP, serum amiloid-A (SAA) gibi değişik inflamatuvar belirteçlerle beraber artmış istirahat kalp hızı kardiyovasküler olayların yeni öngörücüsü olarak ortaya çıkmışlardır. ${ }^{15,16}$ Artmış kalp hızının shear-stress'i artırdığı, arterial kompliansı azalttı̆̆ı ve aterosklerotik süreci hızlandırdığı düşünülmektedir. Maymunlarda yapılan bir araştırmada kalp hızı artışının aterosklerotik plak oluşumuna neden olduğu ve plak gelişimini hızlandırdığı, kontrol grubuna göre ise koroner lezyon ciddiyet ve sayısının daha fazla olduğu saptanmıştır. ${ }^{15}$ Yaş ile birlikte parasempatik aktivitenin azalıp birlikte sempatik aktivitenin artmasına rağmen kalp hızında bir artış gözlenmemektedir. Bizim çalışmamızı yaş grubuna göre incelediğimizde kalp hızı ve kalp hızı değişkenliği ile yaş arasında anlamlı bir fark saptanmamıştır. Sağlıklı bireylerde normal KiMK 0.25-1.0 mm olarak kabul edilir. KiMK yaşla ilişkilidir ve yıllık yaklaşık 0.01-0.02 mm artış gösterir. ${ }^{17} \mathrm{Bu}$ nedenle yetişkinlerde normal olarak kabul edilen $1.0 \mathrm{~mm}$ sınıгı gençlerde normal olarak kabul edilemez. Bugün için yaşa göre ayarlanmış bir ölçek bulunmasa da özellikle gençlerde $0.75 \mathrm{~mm}$ üzerindeki değerler anormal olarak kabul edilmektedir. Bazı çalışmalarda ise anormal demek için araştııılan topluluğun ortalama değerlerinin üzerinde olması gerektiği savunulmaktadır. ${ }^{17,18}$ Mart 2011 tarihinde yayınlanan Ortiz ve ark. yapmış olduğu bir çalışmada yaşları 30-80 arasında olan 356 hipertansif hasta gece/gün kalp hızları oranına göre 3 gruba ayrılmış ve 3 grup KiMK, augmentasyon indeksi ve NDH açısından karşılaştıııImıştı. ${ }^{19}$ KiMK, augmentasyon indeksi ve gece/gün kalp hızı oranı ile pozitif kolere, NDH ise gecelik kalp hızı oranı ile pozitif korele bulunmuştur. 24 saatlik kalp hızında her 10 vuru azalma $0.42 \mathrm{~m} / \mathrm{s}$ 'lik NDH'nda azalmaya yol açmaktadır. Bizim çalışmamızda median gecelik kalp hızına göre hastalar 2 gruba ayrıldığında hastaların yaş, cinsiyet, HDL, LDL düzeyi, NDH ve augmentasyon indeksi arasında anlamlı farklılık saptanmamakla birlikte KiMK'nda anlamlı fark saptanmıştır ( $p: 0.041)$. Daha önceki çalışmalarla benzer çıkmasa da bu sonuç hasta sayısının azlığına ve çalışmaya dahil edilen hastaların daha çok evre 1 hipertansiflerden oluşmasına bağlanabilir.

Prematür koroner arter hastalığı saptanan hastaların çoğunda herhangi bir risk faktörü tanımlanamamış olması ile tetiklenen yeni çalışmalarla beraber inflamatuvar markerler, KiMK, NDH, aug- 
mentasyon indeksleri gibi yeni risk faktörleri geliştirilmiştir. Buna rağmen halen yeni ve daha güçlü risk faktörlerine gereksinim duyulmaktadır. Bunlardan biri olarak da kalp hızı ve kalp hızı değişkenliği gelecek vadetmektedir. Çalışmamızda kalp hızı ve kalp hızı değişkenliği ile kardiyovasküler risk faktörlerinden sadece KiMK arasında anlamlı ilişki bulunmuştur. Mevcut çalışmalara ek olarak yapılacak çalışmalar ile kalp hızının etkin bir şekilde kardiyovasküler hastalık tanısında direkt ya da indirekt olarak klinik kullanım alanı kazandırmak gerekmektedir. Gelecekte farklı topluluklarda yapılacak karşılaştırmalı çalışmalar sonucunda belirlenecek cut-off kalp hızı ve gecelik ortalama kalp hızlarının tespiti ile klinik kullanımımıza girmesi beklenebilir.

\section{Çalışmanın Kısıtlııkları}

Çalışmamızın en önemli kısıtlıı̆̆ı hasta sayımızın az olmasıdır. Ayrıca çalışmaya dahil edilen hastaların büyük bir kısmının da evre 1 hipertansif hastalardan oluşması çalışmanın sonuçlarını etkilemiş olabilir. Hasta gruplarının almakta oldukları ilaç tedavileri kesilmediği veya standart bir tedavi haline getirilmediği özellikle vurgulanmalıdır. Hasta sayısının artırıı tedaviye dirençli hastaların da çalışmaya dahil edilmesi halinde daha anlamlı sonuçlara ulaşılabileceği düşünülmektedir.

\section{Çıkar Uyuşmazlığı}

Yazarlardan hiçbirinin çıkar uyuşmazlığı bulunmamaktadır.
Sakarya Tıp Dergisi

2018;8(2):303-310

çil ve Ark.

Hipertansif Hastalarda Kalp Hızı Değiskenliği ile

Kardiyovasküler Risk Faktörlerinin iliş̧kisi 
1. Swedberg K, Komajda M, Böhm M, Borer JS, Ford I, Dubost-Brama A, et al. Ivabradine and outcomes in chronic heartfailure (SHIFT): a randomised placebo-controlled study, Lancet. 2010 Sep 11;376(9744):875-85.

2. La Rosa JC, Grundy SM, Waters DD, Shear C, Barter P, Fruchart JC, et al. Intensive lipid lowering with atorvastatin in patients with stable coronary disease. N Engl J Med. 2005 Apr 7;352(14):1425-35. Epub2005 Mar 8.

3. Foks K. Ford I, Steg PG, Tendera M, Ferrari R. Ivabradine for patients with stable coronary artery disease and left-ventricular systolic dysfunction (BEAUTIFUL): a randomised, double-blind, placebo-controlled trial, Lancet. 2008 Sep 6;372(9641):807-16. Epub 2008 Aug 29.

akarya TIp Dergisi 2018;8(2):303-310

4. Heart rate variability: standarts of measurement, physiological interpretation and clinical use. Task Force of European Society of Cardiology and North American Society of Pacing and Electrophysiology. Circulation 1996;93:1043-1065.

5. Kleiger RE, Stein PK, Bosner MS, Rottman JN. Time domain measurements of heart rate variability. Cardiol Clin 1992 Aug;10(3):487-98.

6. Chae CU, Pfeffer MA, Glynn RJ, Mitchell GF, Taylor JO, Hennekens CH. Increased pulse pressure and risk of heart failure in the elderly. JAMA 281:634-639;1999.

7. Kostis J, Lawrence-Nelson J, Ranjan R, Wilson A, Kostis W, Lacy C. Association of increased pulse pressure with the development of heart failure in SHEP. Systolic Hypertension in the Elderly (SHEP) Cooperative Research Group. Am J Hypertens 14: 798-803; 2001.

8. Blacher J, Guerin AP, Pannier B, Marchais SJ, Safar ME, London GM. Impact of aorticstiffness on survival in end-stage renal disease. Circulation 99: $2434-2439 ; 1999$.

9. Forette F, Seuks ML, Staessen JA, Thijs L, Birkenhager WH, Babarskiene MR, et al. Prevention of dementia in randomised double-blind placebo-controlled Systolic Hypertension in Europe (Syst-Eur) trial. Lancet 352:1347-1351; 1998.

10. Benetos A, Gautier S, Ricard S, Topouchian J, Asmar R, Poirier O, et al. Influence of angiotensin-converting enzyme and angiotensin 2 type 1 receptor gene polymorphisms on aortic stiffness in normotensive and hypertensive patients. Circulation 1996;94:698-703.
11. Dart AM, Qi KSL. Determinants of arterial stiffness in Chinese migrants to Australia. Atherosclerosis 1995; 117:263-272.

12. Hamazaki T, Urakaze M, Sawazaki S, Yamazaki K, Taki H, Yano S. Comparison of pulse wave velocity of the aorta between in habitants of fishing and farming villages in Japan. Atherosclerosis 1988; 73:157-160.

13. Mutangadura, Gladys B editors. Reducingrisks, promoting healthy life World Health Report 2002: Geneva, World Health Organization, 2002

14. Kannel WB. Range of serum cholesterol values in the poulation developing coronary artery disease. Am J Cardiol 1995;76:69-77.

15. Chait A, Han CY, Oram JF, Heinecke JW. Thematic rewiew series: The immune system andatherogenesis. Lipoprotein-associated inflammatory proteins: Markers or mediators of cardiovascular disease? J LipidRes 2005;46:389- 403

16. Willerson JT, Ridker PM. İnflammation as a cardiovascular risk factor versus risk factor. Circulation 2004:109 (21 Suppl 1):p2-10

17. Schaefer EJ, Lamon-Fava S, Ordovas JM, Chon SD, Shaefer MM, Castell WP, et al. Factors associated with low and elevated plasma high density lipoprotein cholesterol and apolipoprotein A-I levels in the Framingham Offspring Study. J Lipid Res. 35:871-882, 1994

18. Mahley RW, Mahley LL, Bersot TP, Pepin GM, Palaoglu KE. The Turkish lipid problem: low levels of high density lipoproteins. Turk J Endocr Metab. 1:1-12, 2002

19. García-Ortiz L, García-García A, Ramos-Delgado E, Patino-Alonso MC Recio-Rodríguez JI, Rodríguez-Sánchez E, et al. Relationship of night/day heart rate ratio with carotid intima media thickness and markers of arteria stiffness. Atherosclerosis 2011;53:241-264 